\title{
Implicit and Explicit AlcoholRelated Cognitions in heavy and Light Drinkers.
}

Citation for published version (APA):

Wiers, R. W. H. J., van Woerden, N., Smulders, F. T. Y., \& de Jong, P. J. (2002). Implicit and Explicit AlcoholRelated Cognitions in heavy and Light Drinkers. Journal of Abnormal Psychology, 111(4), 648-658. https://doi.org/10.1037/0021-843X.111.4.648

Document status and date:

Published: 01/01/2002

DOI:

10.1037/0021-843X.111.4.648

Document Version:

Publisher's PDF, also known as Version of record

\section{Please check the document version of this publication:}

- A submitted manuscript is the version of the article upon submission and before peer-review. There can be important differences between the submitted version and the official published version of record.

People interested in the research are advised to contact the author for the final version of the publication, or visit the DOI to the publisher's website.

- The final author version and the galley proof are versions of the publication after peer review.

- The final published version features the final layout of the paper including the volume, issue and page numbers.

Link to publication

\footnotetext{
General rights rights.

- You may freely distribute the URL identifying the publication in the public portal. please follow below link for the End User Agreement:

www.umlib.nl/taverne-license

Take down policy

If you believe that this document breaches copyright please contact us at:

repository@maastrichtuniversity.nl

providing details and we will investigate your claim.
}

Copyright and moral rights for the publications made accessible in the public portal are retained by the authors and/or other copyright owners and it is a condition of accessing publications that users recognise and abide by the legal requirements associated with these

- Users may download and print one copy of any publication from the public portal for the purpose of private study or research.

- You may not further distribute the material or use it for any profit-making activity or commercial gain

If the publication is distributed under the terms of Article $25 \mathrm{fa}$ of the Dutch Copyright Act, indicated by the "Taverne" license above, 


\title{
Implicit and Explicit Alcohol-Related Cognitions in Heavy and Light Drinkers
}

\author{
Reinout W. Wiers, Nieske van Woerden, Fren T. Y. Smulders, and Peter J. de Jong \\ Maastricht University
}

\begin{abstract}
Implicit and explicit alcohol-related cognitions were measured in 2 dimensions: positive-negative (valence) and arousal-sedation, with 2 versions of the Implicit Association Test (IAT; A. G. Greenwald, D. E. McGhee, \& J. L. Schwartz) and related explicit measures. Heavy drinkers $(n=24)$ strongly associated alcohol with arousal on the arousal IAT (especially men) and scored higher on explicit arousal expectancies than light drinkers $(n=24)$. On the valence IAT, both light and heavy drinkers showed strong negative implicit associations with alcohol that contrasted with their positive explicit judgments (heavy drinkers were more positive). Implicit and explicit cognitions uniquely contributed to the prediction of 1-month prospective drinking. Heavy drinkers' implicit arousal associations could reflect the sensitized psychomotor-activating response to drug cues, a motivational mechanism hypothesized to underlie the etiology of addictive behaviors.
\end{abstract}

During the past 2 decades, alcohol-related cognitions have received considerable attention in psychological theories on the etiology of alcohol use disorders. Several cognitive-motivational constructs have been proposed to predict alcohol use and abuse, such as outcome expectancies (e.g., Goldman, Del Boca, \& Darkes, 1999), attitudes (e.g., Burden \& Maisto, 2000), and motives (e.g., Cooper, Frone, Russell, \& Mudar, 1995). These approaches have been successful in the prediction of alcohol use and abuse but have also been criticized on a number of conceptual and methodological grounds (e.g., Leigh, 1989b). Furthermore, the validity of self-report measures, commonly used to assess these constructs, has been criticized on more general grounds (e.g., Nisbett \& Wilson, 1977). For this reason, and because it is unclear to what extent a questionnaire can tap underlying cognitive motivational processes, Greenwald and Banaji (1995) proposed using implicit measures that do not rely on self-report to assess attitudes and related concepts in addition to using explicit measures. In this study, implicit and explicit alcohol-related cognitions were assessed in light and heavy drinkers and related to prospective alcohol use.

Reinout W. Wiers, Nieske van Woerden, and Fren T. Y. Smulders, Department of Experimental Psychology, Maastricht University, Maastricht, the Netherlands; Peter J. de Jong, Department of Medical, Clinical, and Experimental Psychology, Maastricht University.

The data in this article were presented in a symposium on implicit and explicit alcohol-related cognitions at the 24th Annual Scientific Meeting of the Research Society on Alcoholism, in Montreal, Quebec, Canada, June 23-28, 2001.

We thank Gerard van Breukelen for statistical advice; Daphne Schmutzer and Esther van den Wildenberg for help with data collection; and Susan Ames, Pepijn van Empelen, Remco Havermans, Alan Stacy, Nicole Theunissen, and Martin Zack for comments on earlier versions of the article.

Correspondence concerning this article should be addressed to Reinout W. Wiers, Department of Experimental Psychology, UNS 40, Universiteit Maastricht, P.O. Box 616, 6200 MD Maastricht, the Netherlands. E-mail: R.Wiers@psychology.unimaas.nl

\section{Explicit Alcohol-Related Cognitions}

The cognitive-motivational construct that has received the most attention in the alcohol field is that of outcome expectancies (referred to hereafter as expectancies), or the beliefs individuals hold about the effects of alcohol on behavior, moods, and emotions (Leigh, 1989b). Since the development of the first alcohol expectancy questionnaires, hundreds of studies have investigated the relationship between expectancies and alcohol use (Goldman et al., 1999). Expectancies predict up to $50 \%$ of the variance in alcohol use when structural equation modeling (SEM) is used (e.g., Goldman et al., 1999; Leigh \& Stacy, 1993; Wiers, Hoogeveen, Sergeant, \& Gunning, 1997). Expectancies measured in young adolescents significantly predict drinking patterns up to 9 years later, after controlling for earlier alcohol and drug use (Stacy, Newcomb, \& Bentler, 1991). Given this predictive power, several authors have argued that expectancies are an important cognitive mediator in the etiology of alcohol use disorders, mediating more distal biological and cultural influences (Goldman et al., 1999; Sher, 1991; Wiers, Gunning, \& Sergeant, 1998). Current issues in expectancy research include the relationship between expectancies and other cognitive-motivational constructs, their structure, and their assessment using implicit and explicit measures.

\section{Expectancies, Attitudes, and Motives}

Attitudes are global evaluations of objects in people's environment that perform an important approach-avoidance function (e.g. Wilson, Lindsey, \& Schooler, 2000). Attitudes can be measured in different ways: by directly assessing a global evaluation or, more indirectly, by multiplying specific expectancies (beliefs) with respect to their subjective value in forming attitudes that predict alcohol use and abuse through intentions (e.g., Fishbein \& Ajzen, 1975). Note that in the indirect conceptualization, expectancies and attitudes are almost identical (the difference is value, but most expectancies have similar values to most people; Goldman et al., 1999). However, several studies have shown that global attitudes and specific expectancies predict unique variance in alcohol use 
and are hardly correlated (Leigh, 1989a; Stacy, Widaman, \& Marlatt, 1990; Wall, Hinson, \& McKee, 1998). Stacy et al. (1990) found that expectancies better predicted 1-month prospective alcohol use than did global attitudes, but Burden and Maisto (2000) found the opposite.

A third cognitive-motivational construct concerns motivation or motives (e.g., Cooper et al., 1995). In this view, alcohol is drunk to enhance positive emotions (positive reinforcement motives; e.g., fun) or to alleviate negative emotions (negative reinforcement motives, e.g., tension reduction). In cross-sectional studies, Cooper et al. found that both motives predicted alcohol use in adolescents and adults and that related expectancies (of positive and negative reinforcement) were the main predictors of both motives, which makes it questionable to what extent the two concepts can be meaningfully distinguished (Goldman et al., 1999). However, distinguishing between positive and negative reinforcement expectancies (which are both positive expectancies) appears important, apart from distinguishing positive and negative expectancies.

\section{Expectancy Structure}

The influential review of Leigh (1989b) criticized earlier expectancy research for relying on exploratory factor analysis and putting too much emphasis on different subtypes of positive expectancies. In response to these criticisms, two approaches were taken: a factor analytic approach using SEM, and an approach focusing on the underlying memory structure of expectancies. In the factor analytic approach, expectancies have been conceptualized as higher order factors in relation to valence (positive and negative; e.g., Leigh \& Stacy, 1993) or as higher order factors in relation to both valence and dose of alcohol (Wiers, Hartgers, Van den Brink, Gunning, \& Sergeant, 2000; Wiers et al., 1997). In both models, the higher order factors load on more specific first-order factors (e.g., "fun," "sex"). Expectancies may also be differentiated with respect to phase of intoxication: During the rising limb of the blood alcohol curve (BAC), participants expect more (positive) arousal; later, during the falling limb of the BAC, they expect more sedation (Earleywine \& Martin, 1993).

A second response to Leigh's (1989b) criticisms was the development of an approach in which expectancies are viewed as nodes in a semantic network (Rather, Goldman, Roehrich, \& Brannick, 1992). In this approach, participants respond on a Likert scale to the phrase "Drinking alcohol makes me ...." for a large number of adjectives. The expectancy network is constructed using multidimensional scaling (MDS). Expectancies were found to consistently map on two dimensions: positive-negative and arousalsedation, with heavy drinkers expecting more (positive) arousal and light drinkers more (positive) sedation (Goldman et al., 1999). The same two dimensions have been distinguished in emotion research, which is not surprising given that an important function of alcohol (and other drugs) is to alter emotional states (e.g., Goldman et al., 1999; Lang, Patrick, \& Stritzke, 1999).

\section{Implicit Alcohol-Related Cognitions}

A common potential threat to the assessment of all cognitivemotivational variables introduced so far is that they rely on selfreport. One may question to what extent a questionnaire can tap underlying cognitive-motivational processes (Greenwald \& Ba- naji, 1995). Potential problems with explicit measures are selfpresentation (e.g., Greenwald, McGhee, \& Schwartz, 1998) and reactivity (for an example in alcohol-expectancy research, see Wiers, Sergeant, \& Gunning, 2000). For these reasons, Greenwald and Banaji (1995) called for the use of more indirect assessment of attitudes and related concepts in addition to explicit assessment. They defined implicit cognitions as "the introspectively unidentified (or inaccurately identified) trace of past experience that mediates a response" (p. 5). In addition, the use of implicit as well as explicit measures may be of importance because they could tap different underlying cognitive-motivational processes (Stacy, 1997; Wilson et al., 2000). ${ }^{1}$

Several approaches have been taken to assess alcohol-related cognitions in more implicit ways. Stacy and colleagues used a variety of memory association tasks to tap implicit alcohol cognitions (e.g., Ames \& Stacy, 1998; Stacy, 1997). The number of alcohol-related associations (memory bias) predicted alcohol use 1 month prospectively, after controlling for previous use and explicit expectancies (Stacy, 1997). Other examples of the use of implicit techniques in alcohol research are semantic priming (e.g., Zack, Tonneato, \& McLeod, 1999) and implicit priming (e.g., Roehrich \& Goldman, 1995).

\section{The Implicit Association Test}

In attitude research, several indirect measures have been developed (Fazio, 2001; Greenwald \& Banaji, 1995). The implicit measures used here are varieties of the Implicit Association Test (IAT; Greenwald et al., 1998). The IAT is a categorization task that offers a method for indirectly assessing the relative strength of associations between concepts. Participants sort stimuli into four concepts, using two responses. Two concepts are the attributes (typically, positive-negative), and two concepts are the targets (e.g., typical names for Blacks and Whites in the race IAT). It is the participant's task to indicate as quickly as possible to which category a word belongs. In the critical phases of the IAT, target and attribute words are mixed (e.g., "For a Black's name or a positive word, press the left response key"; "For a White's name or a negative word, press the right response key"). The IAT effect is the difference in reaction times (RTs) for the two combinations of targets and attributes. ${ }^{2}$ The IAT depends on the assumption that RTs are facilitated when strongly associated concepts share the same response key (e.g., "White name" and "positive") and hampered when the concepts that share a response key are either weakly associated or bipolarly opposed (e.g., "Black name" and

\footnotetext{
${ }^{1}$ There are different views on the relationship between implicit and explicit (alcohol-related) cognitions. In addiction research, Stacy (1997, p. 69) interpreted his findings as support for distinct implicit and explicit processes that differentially influence behavior. Goldman et al. (1999, p 236) questioned this interpretation and argued that processes cannot be separated from their measurement. A similar discussion takes place in basic cognitive research between adherents of the process-dissociation approach and those of the task-dissociation approach (Reingold \& Toth, 1996). In clinical research, it seems particularly relevant to investigate whether implicit and explicit measures predict unique variance in outcome measures (e.g., Stacy, 1997) or different aspects of behavior (e.g., Dovidio et al., 2001).
}

2 The IAT test can be tried out on http://buster.cs.yale.edu/implicit 
"positive"). In this example, a large difference in RT between phases combining "Black-positive, White-negative" and "Whitepositive, Black-negative" indicates a strong implicit racial attitude (Greenwald et al., 1998).

The psychometric properties of the IAT are rather good. Several studies reported that the IAT has fairly good test-retest reliability (about .70), and split-half reliabilities around .90 (Bosson, Swann, \& Pennebaker, 2000; Greenwald \& Nosek, 2001). Speaking to the internal validity of the IAT, it has been demonstrated that the IAT effect is not influenced by the familiarity of items used and that the IAT cannot be faked (Greenwald \& Nosek, 2001). Cunningham, Preacher, and Banaji (2001), using SEM, showed good convergent validity of the IAT and other measures of implicit attitudes. Disciminant validity between implicit associations as measured with the IAT and self-report measures has been demonstrated in a large number of studies. Typically, the correlation of the IAT and a related explicit measure is small but not zero (about .25; Dovidio, Kawakami, \& Beach, 2001). Predictive validity has been shown in studies in which groups differed in expected ways in their implicit associations (e.g., Greenwald et al., 1998). Finally, there are indications that implicit and explicit measures predict different aspects of behavior (Dovidio et al., 2001).

Recently, varieties of the IAT have been applied to experimental psychopathology research of social anxiety (e.g., de Jong, Pasman, Kindt, \& Van den Hout, 2001), phobia (Teachman, Gregg, \& Woody, 2001), eating disorders (Roefs \& Jansen, 2002), and depression (Gemar, Segal, Sagrati, \& Kennedy, 2001). To our knowledge, this is the first application of the IAT to alcohol research.

\section{This Study}

We measured implicit and explicit alcohol-related cognitions in two dimensions: valence (positive-negative) and arousal (arousalsedation). These two dimensions were chosen for several reasons. They were consistently found in semantic memory studies of expectancies (Goldman et al., 1999) and in emotion research (Lang et al., 1999). Furthermore, there is evidence that distinct neurobiological processess underlie these two dimensions and that the sensitized initial arousal reactions to drug-related stimuli are crucial in the development of addiction (Robinson \& Berridge, 1993, 2001). Both dimensions were measured implicitly with two IATs (valence IAT and arousal IAT) and explicitly with paper-andpencil tests using the same words. A general expectancy questionnaire was included to measure negative and positive (both positive and negative reinforcement) expectancies for a low and a high dose of alcohol (Wiers et al., 1997). Participants were light and heavy drinking undergraduate university students. On the basis of MDS research, we predicted that heavy drinkers would score higher on arousal expectancies than light drinkers and that both light and heavy drinkers would be moderately positive about alcohol. Finally, we explored the predictive power of participants' implicit and explicit alcohol-related cognitions pertaining to 1-month prospective alcohol use.

\section{Method}

\section{Participants}

Participants were 48 volunteer undergraduate students (24 men, 24 women) of Maastricht University. They were invited on the basis of their alcohol use and problem scores, reported in a screening 3 months before the study $(N=182)$. We selected 24 heavy drinkers ( 12 men, 12 women) with high weekly alcohol use and high scores on alcohol-related problems (alcohol use: $M=32.0$ standard servings $^{3}$ per week, $S D=12.9$; alcohol problems: $M=15.8, S D=8.6$ ) and 24 light drinkers ( 12 men, 12 women) with low scores on weekly alcohol use and on alcohol-related problems (alcohol use: $M=5.1, S D=4.4$; alcohol problems: $M=3.6, S D=2.8$ ). Light drinkers were selected to drink at least one alcoholic drink a week. Male participants scored nonsignificantly higher on alcohol consumption than female participants (19.0 vs. 16.6 drinks per week, $p>.30)$ and alcohol-related problems (11.2 vs. 8.2, $p>.25)$. Mean age was 21.5 years, with no difference between light and heavy drinkers $(p>.50)$.

\section{Materials and Measures}

Alcohol use. Alcohol use was measured with a self-report questionnaire (Wiers et al., 1997) based on the timeline follow-back method (Sobell \& Sobell, 1990). Self-report measures have been found valid when used in a research setting with sober participants who are given assurance of confidentiality (Sobell \& Sobell, 1990). These requirements were fulfilled in our study. Participants indicated on grids how many standard drinks they consumed of different types of alcoholic drinks during each day of the past week, and for each day how many drinks they drank on a typical day. With this questionnaire, estimates for drinking prior to the experiment were generated. In addition, participants were asked to keep an alcohol diary, in which they filled out the number of different drinks (and circumstances) during the 28 days after the second experimental session. From this diary, prospective alcohol use was calculated.

Alcohol-related problems. The Rutgers Alcohol Problem Index (RAPI; White \& Labouvie, 1989) was used, which measures social and health-related problems adolescents and young adults had experienced with alcohol (e.g., not able to do homework because of a hangover). Participants indicated on a 5-point Likert scale how often they had experienced each problem. The scale has a high reliability (.80 or higher) and accurately discriminates between clinical and nonclinical samples. Reported means for clinical samples on the RAPI are between 21 and 26, indicating that the average level of alcohol-related problems in heavy drinkers in our study was at a subclinical level $(M=15.8)$.

Implicit association tasks. Two IATs were presented in balanced order (valence IAT and arousal IAT). Both contained two sets of two word categories. The target words always consisted of alcoholic drinks (labeled alcohol: beer, wine, port, whisky, vodka, rum) and sodas (labeled sodas: "Coke," "Cassis," "Sinas" [the last two are lemonades], "Spa" [sparkling water], tonic, and juice). The attribute set consisted of either positive and negative words (valence IAT) or arousal and sedation words (arousal IAT). For the positive-negative dimension, the following words were used: positive words (labeled positive) were "sociable," "good," "pleasant," "nice," "enjoyable," "sympathetic"; negative words (labeled negative) were "antisocial," "bad," "unpleasant," "stupid," "obnoxious," "tedious." Arousal words (labeled active) were "energetic," "lively," "funny," "cheerful," "loose," "aroused"; sedation words (labeled passive) were "relaxed," "sleepy," "woozy," "quiet," "calm," "listless." The Dutch words were matched for prevalence and number of syllables.

Each IAT consisted of nine phases that came in one of two orders (see Table 1; we closely followed the design of Greenwald et al., 1998). Each IAT consists of two blocks in which the order of the two combination phases is reversed. The four mixed phases necessary to generate the two IAT effects per task were given in one of two orders: CRRC or RCCR, where $\mathrm{C}$ stands for combination and $\mathrm{R}$ for reversed combination. Every phase consisted of one practice block and either a single measurement block (single-dimension discrimination phases) or two measurement

\footnotetext{
${ }^{3}$ A standard alcohol serving in Holland contains somewhat less alcohol than a standard English or American serving: $12 \mathrm{~g}$ versus $14 \mathrm{~g}$.
} 
Table 1

Measuring Alcohol Associations With the Valence and Arousal Implicit Association Tests (IATs)

\begin{tabular}{|c|c|c|c|c|}
\hline \multirow[b]{2}{*}{ Phase } & \multicolumn{2}{|c|}{ Valence IAT } & \multicolumn{2}{|c|}{ Arousal IAT } \\
\hline & Concept, left hand & Concept, right hand & Concept, left hand & Concept, right hand \\
\hline 1 & alcohol & soda & alcohol & soda \\
\hline 2 & positive & negative & active & passive \\
\hline $3\left(\mathrm{C}_{1}\right)$ & alcohol or positive & soda or negative & alcohol or active & soda or passive \\
\hline & soda & alcohol & soda & alcohol \\
\hline $5\left(\mathrm{R}_{1}\right)$ & soda or positive & alcohol or negative & soda or active & alcohol or passive \\
\hline & soda & alcohol & soda & alcohol \\
\hline $7\left(\mathrm{R}_{2}\right)$ & soda or positive & alcohol or negative & soda or active & alcohol or passive \\
\hline & alcohol & soda & alcohol & soda \\
\hline $9\left(\mathrm{C}_{2}\right)$ & alcohol or positive & soda or negative & alcohol or active & soda or passive \\
\hline
\end{tabular}

Note. The following explanation is for the valence IAT (for an explanation of the arousal IAT, replace positive with active and negative with passive): In Phase 1, participants press the left response key when the target word on the screen is an alcoholic drink (e.g., "beer") and the right response key when the target word is a soda (e.g., "juice"). In Phase 2, participants press the left response key when the target is positive (e.g., "good") and the right response key when the target is negative (e.g., "bad"). In Phase 3 (the first combination phase, C), participants press the left response key when the target is an alcoholic drink or a positive word, and the right response key when the target is a soda or a negative word. Phase 4 is a reversal of Phase 1 (alcohol and soda are assigned to the other side). In Phase 5 (the first reverse combination, R), participants press the left response key when the target is a soda or a positive word, and the right response key when the target is an alcoholic drink or a negative word. Phase 6 repeats Phase 4, Phase 7 repeats Phase 5, Phase 8 repeats Phase 1, and Phase 9 repeats Phase 3. The first IAT effect is the difference in reaction times between the $3 \mathrm{rd}\left(\mathrm{C}_{1}\right)$ and the 5 th $\left(\mathrm{R}_{1}\right)$ phase. The second IAT effect is the difference in reaction times between Phase $9\left(C_{2}\right)$ and Phase $7\left(R_{2}\right)$.

blocks ( $\mathrm{R}$ and $\mathrm{C}$ Phases 3, 5, 7, and 9). Each block consisted of 48 words. Words were selected randomly for each participant (all identical to Greenwald et al., 1998).

Explicit alcohol-related cognitions. The attribute words used in the two IATs were used to construct explicit measures of the valence and arousal dimensions. In line with attitude research, the explicit measure of the valence dimension consisted of 6 semantic differentials (e.g., "drinking alcohol is good_— bad"), with an unmarked 11-cm visual analogue scale (VAS) as the response format. This measure is very similar to explicit measures of global attitudes (e.g., Stacy et al., 1990; Wall et al., 1998) and is labeled global attitudes. In line with expectancy research, arousal and sedation were measured with unipolar VAS scales (also $11 \mathrm{~cm}$ and unmarked; e.g., "After drinking alcohol, I become energetic"; disagreeagree). ${ }^{4}$ The reliability of these three explicit scales (Global Attitudes, VAS-Arousal, VAS-Sedation) was reasonably good, and they were not significantly correlated (Table 2). In addition, participants filled out a more extensive questionnaire in which four types of expectancies were measured: positive and negative expectancies for low and high doses of alcohol (Wiers et al., 1997). ${ }^{5}$ In line with the motivational framework (e.g., Cooper et al., 1995), positive expectancies were differentiated into a positive reinforcement scale (e.g., fun, sex) and a negative reinforcement scale (e.g., tension reduction). In order to reduce the number of scales, scores were combined for a low and a high dose of alcohol. The internal consistencies of the three resulting scales were all reasonably good (.78-.91; see Table 2).

\section{Procedure}

Participants individually performed the two versions of the IAT in a standard laboratory at Maastricht University on 2 separate days approximately 1 week apart. After each IAT version, the related explicit measure followed (e.g., valence IAT followed by explicit global attitudes; total time was approximately $25 \mathrm{~min}$ ). We judged that it was better to always administer the implicit measure first because the carryover effects of explicit measures to implicit measures appear to be larger than vice versa (Bosson et al., 2000). The second session ended with the more extensive questionnaires of expectancies, alcohol use, and alcohol-related problems, adding about 30 min to the testing. Participants were asked to keep an alcohol diary in the month after the end of the experiment and send this (anonymously) to the investigators. Participants received Hfl 25 (about US\$10) for participation.

IAT stimuli. The IAT was programmed in ERTS 3.18 (Beringer, 1996). Words were presented in black smallfont (14-point) in the middle of the screen. Feedback appeared in red midfont letters (16-point) 1 inch below the stimuli words. The category word or words were always presented at the top of the screen, appropriately positioned on the left or the right side of the screen, depending on the required response (as in Greenwald et al., 1998). The interstimulus interval was $250 \mathrm{~ms}$. In case of a wrong response, the word "ERROR" appeared on the screen. After responses that were too fast $(<150 \mathrm{~ms})$ or too slow $(>3 \mathrm{~s})$, feedback followed ("TOO FAST" or "TOO SLOW") with a warning beep.

Procedural variables and data reduction. Half of the participants received the valence IAT first, and half received the arousal IAT first (the factor session). For each IAT, half of the participants received the RCCR order, and half received the CRRC order (the factor order). A third between-subjects variable was response key (e.g., "soda" started on the left or right side). All procedural variables were balanced. Data reduction

\footnotetext{
${ }^{4}$ Leigh $(1989 a, 1989 b)$ demonstrated that the use of a bipolar scale is unwarranted in expectancy research by comparing three scales, of which only the bipolar scale failed to predict alcohol consumption in contrast to two unipolar scales (see also Wiers et al., 1997). However, in attitude research, the format most commonly used is a bipolar scale. We decided to use the standard formats used in both research traditions.

${ }^{5}$ In fact, the follow-up version of the original expectancy questionnaire was used, which has the same set-up but some different items. The more recent version includes three lower order factors for each of the four higher order factors (positive and negative expectancies for low and high doses of alcohol). Positive expectancies (both for low and high doses) include a scale of negative reinforcement and two other scales of positive reinforcement.
} 
Table 2

Pearson Correlations and Cronbach Alphas for Implicit and Explicit Cognitions and Alcohol (Ab)use at Time 1

\begin{tabular}{|c|c|c|c|c|c|c|c|c|c|c|c|}
\hline & $\begin{array}{l}\text { No. of } \\
\text { items }\end{array}$ & $\alpha$ & 1 & 2 & 3 & 4 & 5 & 6 & 7 & 8 & 9 \\
\hline 1. Valence IAT & 2 & .58 & - & & & & & & & & \\
\hline 2. Arousal IAT & 2 & .56 & $-.41 * *$ & - & & & & & & & \\
\hline 3. Global Attitudes & 6 & .78 & $-.38 * *$ & .18 & - & & & & & & \\
\hline 4. VAS Arousal & 6 & .88 & .10 & -.03 & .05 & - & & & & & \\
\hline 5. VAS Sedation & 6 & .82 & -.03 & -.17 & .09 & -.20 & - & & & & \\
\hline 6. Pos. Reinforce. Expect. & 17 & .91 & .19 & -.12 & .04 & $.68 * * *$ & -.05 & - & & & \\
\hline 7. Neg. Reinforce. Expect. & 10 & .81 & -.18 & .20 & $.32 *$ & .22 & $.30 *$ & $.49 * * *$ & - & & \\
\hline 8. Neg. Expect. & 15 & .79 & .28 & .01 & $-.32 *$ & .18 & .08 & $.40 * *$ & $.33 *$ & - & \\
\hline 9. Alcohol (Ab)use & 4 & .93 & $-.37 *$ & $.30 *$ & $.52 * * *$ & .23 & .12 & .15 & $.49 * * *$ & -.16 & — \\
\hline
\end{tabular}

Note. The valence IAT effect was calculated as the mean reaction times (RTs, in milliseconds) in the C phases (alcohol-positive, soda-negative) minus the mean RTs in the R phases (alcohol-negative, soda-positive). Hence, a larger value indicates a stronger negative association with alcohol. The negative correlation with alcohol use is in the expected direction. The arousal IAT effect was calculated as the mean RTs in the R phases (alcohol-passive, soda-active) minus the mean RTs in the $\mathrm{C}$ phases (alcohol-active, soda-passive). A larger value indicates a larger implicit arousal association with alcohol. IAT $=$ Implicit Association Test; VAS = Visual Analogue Scales; Pos. Reinforce. Expect. = positive reinforcement expectancies (e.g., fun, sex); Neg. Reinforce. Expect. $=$ negative reinforcement expectancies (e.g., tension reduction); Neg. Expect. = negative expectancies (e.g., insecure, sick, negative mood, risk); Alcohol (Ab)use = the combined score of alcohol use during the past week, average weekly alcohol consumption, number of binges during the past weeks, and alcohol-related problems (Rutgers Alcohol Problem Index).

$* p<.05 . \quad * * p<.01 . \quad * * * p<.001$.

procedures were consistent with other IAT research (Greenwald \& Nosek, 2001): RTs below $300 \mathrm{~ms}$ were recoded to $300 \mathrm{~ms}$, and RTs above 3,000 ms were recoded to $3,000 \mathrm{~ms}$. Only RTs on correct answers were analyzed.

\section{Results}

\section{Explicit Cognitions}

The six scales representing the explicit cognitive-motivational variables were subjected to a 2 (Drinker Type) $\times 2$ (Gender) multivariate analysis of variance (MANOVA). Heavy drinkers differed significantly from light drinkers, $F(6,39)=4.75, p=$ .001 , and men differed significantly from women, $F(6,39)=3.24$, $p=.011$, in the absence of a significant interaction, $F(6,39)=$ $.55, p>.50 .^{6}$ In order to assess the relative contribution of the different variables to the MANOVA, a discriminant analysis was performed that focused on the structure coefficients (Huberty \& Morris, 1989). The relative contributions to the multivariate difference between light and heavy drinkers were (in descending order, with structure coefficients in parentheses): global attitudes (.66), negative reinforcement expectancies (.59), VAS-arousal (.42), positive reinforcement expectancies (.34), negative expectancies (.10), and VAS-sedation (.05). Inspection of the means confirmed the expected direction of the effects: Heavy drinkers had more positive global attitudes and scored higher on positive and arousal expectancies (Table 3). The relative contributions to the multivariate gender difference were as follows: VAS-arousal (.78), positive reinforcement expectancies (.66), VAS-sedation $(-.49)$, negative expectancies (.16), global attitudes $(-.14)$, and negative reinforcement expectancies (-.03). Unexpectedly, women scored higher than men on arousal and positive reinforcement expectancies, and lower on sedation (Table 3).

\section{Implicit Cognitions}

RT data and errors for the valence IAT and the arousal IAT are found in Table 4. Note that the $\mathrm{C}$ phases in the valence IAT (alcohol-positive and soda-negative) were performed more slowly than the $\mathrm{R}$ phases (alcohol-negative and soda-positive), indicating that both light and heavy drinkers had negative implicit associations with alcohol. In the arousal IAT, the expected pattern was found in heavy drinkers: faster responses in the $\mathrm{C}$ phases (alcoholactive and soda-passive) than in the $\mathrm{R}$ phases (alcohol-passive and soda-active), whereas in light drinkers these combinations were performed about equally fast. The pattern of errors generally corresponded to the pattern in RTs (as in other IAT research; Greenwald \& Nosek, 2001).

The IAT effects were analyzed with a 3 (within-subjects) $\times 4$ (between-subjects) mixed analysis of variance (ANOVA), with gender, drinker type, and the procedural variables of order (CRRC or RCCR) and session (valence IAT or arousal IAT in the first session) as between-subjects variables. Dependent variables were the RTs on the four combination phases (C or R) for both IATs. In these analyses, the IAT effect was analyzed as a within-subject factor (C vs. R), with block (first CR or second CR), and IAT type (valence vs. arousal) as other within-subject factors. For ease of interpretation, the combination phases of the valence IAT were entered in the reverse order from those of the arousal IAT (RC vs. $\mathrm{CR})$. In that way, both IAT effects were in the same direction, which made their comparison easier (this procedure is analytically equivalent to an analysis with the same orders for both versions but makes the interactions comparable to other IAT research in which the $\mathrm{C}$ phase involves the faster combination). RTs were log trans-

\footnotetext{
${ }^{6} \mathrm{We}$ checked whether the nonsignificant gender difference in mean alcohol consumption accounted for the multivariate difference in explicit cognitive-motivational variables by running an additional analysis with mean alcohol consumption as a covariate. The multivariate gender difference in performance on the explicit measures remained significant, $F(6$, $38)=2.81, p=.023$. Furthermore, an analysis was run with session as an extra factor (as in the IAT analyses). No session effects were found ( $p>$ $.50)$.
} 
Table 3

Means and Standard Deviations for the Explicit Cognitive Motivational Variables by Gender and Drinker Type

\begin{tabular}{|c|c|c|c|c|c|c|c|c|}
\hline \multirow[b]{2}{*}{ Variable } & \multicolumn{2}{|c|}{$\begin{array}{l}\text { Light drinking } \\
\text { women }\end{array}$} & \multicolumn{2}{|c|}{$\begin{array}{l}\text { Light drinking } \\
\text { men }\end{array}$} & \multicolumn{2}{|c|}{$\begin{array}{l}\text { Heavy drinking } \\
\text { women }\end{array}$} & \multicolumn{2}{|c|}{$\begin{array}{l}\text { Heavy drinking } \\
\text { men }\end{array}$} \\
\hline & $M$ & $S D$ & $M$ & $S D$ & $M$ & $S D$ & $M$ & $S D$ \\
\hline \multicolumn{9}{|l|}{ VAS Scale } \\
\hline Global Attitudes & 57.6 & 10.2 & 59.8 & 12.5 & 69.2 & 12.1 & 71.3 & 9.0 \\
\hline Arousal & 72.0 & 12.3 & 47.4 & 22.8 & 76.2 & 7.9 & 67.0 & 12.8 \\
\hline Sedation & 44.7 & 12.5 & 58.0 & 23.4 & 45.4 & 17.0 & 54.3 & 14.5 \\
\hline Pos. Reinforce. Expect. & 3.2 & 0.7 & 2.5 & 0.9 & 3.5 & 0.6 & 3.0 & 0.4 \\
\hline Neg. Reinforce. Expect. & 1.9 & 0.6 & 2.0 & 0.6 & 2.5 & 0.7 & 2.6 & 0.8 \\
\hline Neg. Expect. & 1.9 & 0.5 & 1.7 & 0.6 & 1.7 & 0.4 & 1.7 & 0.5 \\
\hline
\end{tabular}

Note. The Visual Analogue Scales (VAS) are expressed in millimeters as mean scores $(0-110$; scale midpoint $=55)$. Expectancies are expressed as mean scores on 5-point Likert scales (midpoint $=3$ ). Pos. Reinforce. Expect. = positive reinforcement expectancies (e.g., fun, sex); Neg. Reinforce. Expect. = negative reinforcement expectancies (e.g., tension reduction); Neg. Expect. = negative expectancies (e.g., loss of control, insecure, sick, negative mood, risk).

formed to increase normality of the distribution (as in other IAT research). Results were checked for the untransformed RT data; the pattern of significant effects was exactly the same.

There was a main IAT effect, $F(1,32)=119.44, p<.001$, indicating that $\mathrm{C}$ phases were performed faster than $\mathrm{R}$ phases. The IAT-type main effect was also significant, $F(1,32)=24.15, p<$ .001 , indicating that the IAT effect was larger on the valence IAT than on the arousal IAT. These effects were qualified by a significant IAT Effect $\times$ IAT Type interaction, $F(1,32)=14.89, p=$ .001 , and a significant IAT Effect $\times$ IAT Type $\times$ Drinker Type interaction, $F(1,32)=5.24, p=.029$, the interaction of main interest (depicted in Figure 1). Note that there are essentially three IAT effects: a negative implicit association with alcohol for both light and heavy drinkers, and an implicit alcohol-arousal association in heavy drinkers only.

For each of the two IATs, the significance of the IAT effect was tested for heavy and light drinkers separately with a withinsubjects ANOVA using the mean RTs of $\mathrm{C}$ and $\mathrm{R}$ phases. The effect sizes $(d)$ were calculated as the quotient of the difference between mean RTs of $\mathrm{C}$ and $\mathrm{R}$ phases and the standard deviation of this difference. The negative implicit association with alcohol was significant for light drinkers, $F(1,23)=49.38, p<.001$, and for heavy drinkers, $F(1,23)=14.74, p=.001$, with large effect sizes $(d \mathrm{~s}=1.43$ and .78 , respectively). The implicit alcoholarousal association was significant for heavy drinkers, $F(1$, $23)=16.53, p<.001$ (large effect size: $d=.83$ ), but not for light drinkers, $F(1,23)=1.20, p=.28(d=.22)$. An ANOVA comparing the two mean IAT effects for light and heavy drinkers indicated that light and heavy drinkers did not significantly differ on implicit valence, $F(1,46)=1.87, p=.18$. The hypothesized stronger implicit alcohol-arousal association in heavy drinkers as compared with light drinkers was confirmed, $F(1,46)=3.72, p=$ .03 (one-tailed).

The next question was whether the IAT Effect $\times$ IAT Type $\times$ Drinker Type interaction was moderated by gender. The interaction with gender was not significant (IAT Effect $\times$ IAT Type $\times$ Drinker Type $\times$ Gender, $p>$.50). However, the IAT Effect $\times$ Drinker Type $\times$ Gender $\times$ Session $\times$ IAT Type interaction showed a trend ( $p=.09$ ), and this interaction qualified three other significant interactions: IAT Effect $\times$ Drinker Type $\times$ Gender $\times$

Table 4

Mean Reaction Times (RTs), Standard Deviations, and Errors for Each of the Nine Phases of the Two Implicit Association Tests (IATs)

\begin{tabular}{|c|c|c|c|c|c|c|c|c|c|c|c|c|}
\hline \multirow[b]{3}{*}{ Phase } & \multicolumn{6}{|c|}{ Valence IAT (positive-negative) } & \multicolumn{6}{|c|}{ Arousal IAT (arousal-sedation) } \\
\hline & \multicolumn{3}{|c|}{ Light drinkers } & \multicolumn{3}{|c|}{ Heavy drinkers } & \multicolumn{3}{|c|}{ Light drinkers } & \multicolumn{3}{|c|}{ Heavy drinkers } \\
\hline & RT & $S D$ & Errors & RT & $S D$ & Errors & RT & $S D$ & Errors & RT & $S D$ & Errors \\
\hline 1 & 546.2 & 71.2 & 2.2 & 528.4 & 53.1 & 2.2 & 547.9 & 62.0 & 2.2 & 552.0 & 81.1 & 1.9 \\
\hline 2 & 601.2 & 80.7 & 2.0 & 579.0 & 65.9 & 2.4 & 722.1 & 132.9 & 3.2 & 707.4 & 125.9 & 3.8 \\
\hline $3\left(\mathrm{C}_{1}\right)$ & 760.0 & 152.0 & 6.8 & 735.4 & 122.9 & 7.1 & 715.7 & 118.6 & 4.8 & 675.6 & 104.6 & 7.0 \\
\hline 4 & 537.0 & 72.4 & 2.0 & 512.8 & 51.2 & 2.3 & 560.7 & 73.2 & 2.2 & 526.8 & 76.6 & 2.3 \\
\hline $5\left(\mathrm{R}_{1}\right)$ & 593.9 & 80.0 & 3.8 & 626.5 & 124.6 & 5.0 & 731.8 & 131.4 & 5.5 & 749.1 & 127.3 & 7.1 \\
\hline 6 & 540.5 & 61.3 & 2.1 & 521.0 & 54.2 & 2.2 & 543.1 & 73.1 & 2.2 & 530.8 & 69.6 & 1.9 \\
\hline $7\left(\mathrm{R}_{2}\right)$ & 604.2 & 86.1 & 4.6 & 598.7 & 87.0 & 5.2 & 700.4 & 143.3 & 5.3 & 724.9 & 140.4 & 6.9 \\
\hline 8 & 546.1 & 75.3 & 2.1 & 515.8 & 48.3 & 1.7 & 538.7 & 66.1 & 1.9 & 531.8 & 63.4 & 1.5 \\
\hline $9\left(\mathrm{C}_{2}\right)$ & 725.4 & 124.8 & 6.6 & 678.3 & 97.4 & 7.0 & 673.3 & 113.6 & 5.3 & 652.6 & 98.0 & 5.1 \\
\hline
\end{tabular}

Note. The critical combination phases are the $\mathrm{C}$ and $\mathrm{R}$ phases. The first IAT effect is the difference between the first $\mathrm{C}$ and $\mathrm{R}$ phases, the second IAT effect is between the second $\mathrm{C}$ and $\mathrm{R}$ phases, and so on (see corresponding Table 1). All RTs are in milliseconds. 
Session, $F(1,32)=6.33, p=.017$; IAT Effect $\times$ IAT Type $\times$ Session, $F(1,32)=5.01, p=.032$; and IAT Type $\times$ Session, $F(1$, $32)=84.80, p<.001$. Therefore, the interaction of main interest (IAT Effect $\times$ IAT Type $\times$ Drinker Type) was examined for each of the four Gender $\times$ Session combinations. In the women, the IAT Effect $\times$ IAT Type $\times$ Drinker Type interaction was significant in the first session, $F(1,8)=7.02, p=.029$, but not in the second $(p>.50)$. In the first session, the light drinking women had a stronger negative implicit association with alcohol than the heavily drinking women (147 ms and $63 \mathrm{~ms}$, respectively), and the heavily drinking women had a stronger implicit arousalassociation than the light drinking women $(105 \mathrm{~ms}$ and $63 \mathrm{~ms}$, respectively), hence a similar pattern as in Figure 1. In the second session, both light and heavily drinking women showed a strong negative implicit association with alcohol $(188 \mathrm{~ms}$ and $184 \mathrm{~ms}$, respectively) and essentially no implicit arousal association ( -4 $\mathrm{ms}$ and $21 \mathrm{~ms}$, respectively). In the men, the IAT Effect $\times$ IAT Type $\times$ Drinker Type interaction was significant in the second session, $F(1,8)=6.19, p=.038$, but not in the first $(p>.50)$. Further analyses showed that on the valence IAT, the pattern reversed in the men: In the first session, a larger implicit negative association with alcohol was found for the heavily drinking men than for the light drinking men (100 ms and $38 \mathrm{~ms}$, respectively); the results were the opposite in the second session (12 ms and 185 $\mathrm{ms}$, respectively). On the arousal IAT, the pattern of results was similar across sessions: In both sessions, only the heavily drinking men showed a strong implicit arousal association $(70 \mathrm{~ms}$ in the first session and $117 \mathrm{~ms}$ in the second session). The light drinking men did not show an implicit arousal association in either session (14 and $4 \mathrm{~ms}$, respectively). The pattern on the arousal IAT is consistent with Figure 1 for men in both sessions. In summary, the significant difference between light and heavy drinkers on the arousal IAT is for the men in both sessions and for the women only in the first session. A negative implicit association with alcohol was found for men and women in both sessions, with inconsistent differences in the relative size of this implicit association per session and drinker type. There were a number of other significant order effects in both IATs that were generally consistent with other IAT research. ${ }^{7}$

\section{Associations With Retrospective and Prospective Alcohol Use}

For further correlational analyses, mean IAT effects were calculated as the mean difference between the $\mathrm{C}$ and the $\mathrm{R}$ phases. In Table 2, associations of the different cognitive-motivational variables with retrospective alcohol use and abuse are presented. ${ }^{8}$ Explicit global attitudes and negative reinforcement expectancies were strongly associated with retrospective alcohol use and problems $(p<.001)$. The two implicit measures were moderately correlated with retrospective alcohol use and problems $(p<.05)$, both in the expected direction (implicit arousal positively, and implicit negative valence negatively).

Prospective alcohol use was obtained for $92 \%$ of the participants. Dropouts were 4 heavy drinkers ( 3 men), who did not return the alcohol diary despite numerous reminders. There were no significant differences between these 4 and the 20 remaining heavy drinkers on any of the alcohol-related variables or age (all $p \mathrm{~s}>$ .50). For the remaining 44 participants, prospective alcohol use was computed from the total consumption of alcohol in the 4 weeks following the experiment. The dependent variable was not normally distributed but showed the typical left-skewed distribution of alcohol variables, with values ranging from 0 to 203 drinks $(M=58.4$ drinks, $M d n=31$ drinks $)$. Therefore, prospective alcohol use was log transformed. Note that there was no indication of a bimodal distribution for light and heavy drinkers.

To reduce the number of predictors, we factor analyzed the 8 cognitive-motivational variables (Variables $1-8$ in Table 2), using principal-components analysis followed by oblimin rotation with Kaiser normalization. Four factors with an eigenvalue above 1 were extracted, explaining $81 \%$ of the variance: (a) Positive Reinforcement Expectancies (questionnaire and VAS-Arousal); (b) Global Attitudes Minus Negative Expectancies; (c) Negative Reinforcement Expectancies and VAS-Sedation; and (d) Implicit Associations (mean RTs of valence IAT minus arousal IAT). The corresponding scales were computed using $z$-transformed scores (raw scores were on different scales) and entered into a hierarchical multiple regression analysis.

The first run of the regression analysis indicated that there was one influential outlier, which was removed. In Step 1, age and gender were entered. These variables did not significantly predict prospective alcohol use, $F(2,40)=1.69, p=.20, R^{2}=.08$. In Step 2, the three composed explicit cognitive-motivational variables were entered. This significantly increased the variance ex-

\footnotetext{
${ }^{7}$ In line with other IAT research, there was a significant block effect, $F(1,32)=47.85, p<.001$, indicating that responses were faster in the second block. We only discuss IAT Effect $\times$ Block interactions because interactions not involving the IAT effect are not of interest here. There were two significant IAT $\times$ Block interactions: IAT $\times$ Block $\times$ IAT Type $\times$ Order, $F(1,32)=36.75, p<.001$, which was qualified by a significant IAT $\times$ Block $\times$ IAT Type $\times$ Order $\times$ Drinker Type interaction, $F(1,32)=5.01, p=.032$. These interactions were consistent with the general finding in IAT research, that a larger IAT effect is seen when one has to change from a fast (easy) combination to a slow (difficult) combination. In the arousal IAT, this concerned the switch from alcohol-active (and soda-passive) to alcohol-passive (and soda-active) phases. As indicated earlier, only heavy drinkers showed the IAT effect on the arousal IAT. Accordingly, the IAT effect was larger in the first than in the second block in the CRRC order ( $150 \mathrm{~ms}$ and $77 \mathrm{~ms}$, respectively) and larger in the second than in the first block in the RCCR order $(67 \mathrm{~ms}$ and $3 \mathrm{~ms}$, respectively). In light drinkers, the arousal IAT effect was essentially zero (all $<25 \mathrm{~ms}$ ), except in the second block in the RCCR order $(75 \mathrm{~ms}$, which again concerned a switch from $\mathrm{C}$ to $\mathrm{R}$ ). In the valence IAT, a similar pattern was observed: In both light and heavy drinkers, the valence IAT effect was larger in the first than in the second block in the CRRC order (light drinkers: $203 \mathrm{~ms}$ vs. $119 \mathrm{~ms}$; heavy drinkers: $198 \mathrm{~ms}$ vs. $78 \mathrm{~ms}$ ). In the RCCR order, the expected larger effect in the second block was observed in heavy drinkers ( $99 \mathrm{~ms}$ vs. $20 \mathrm{~ms}$ ) but not in light drinkers (124 ms vs. $130 \mathrm{~ms}$ ). Hence, the order effects in both IATs were generally consistent with other IAT research, and entirely so for heavy drinkers.

${ }^{8}$ For consistency with earlier analyses (and Figure 1), the mean valence IAT effect was calculated as mean RT in $\mathrm{C}$ phases minus mean RT in R phases (a positive value indicating a negative implicit association with alcohol). For the arousal IAT, the mean IAT effect was calculated as mean $\mathrm{RT}$ in $\mathrm{R}$ phases minus mean $\mathrm{RT}$ in $\mathrm{C}$ phases (a positive value indicating a larger implicit arousal association for alcohol). For alcohol use and problems, one composite measure was calculated consisting of the $z$-transformed scores for weekly alcohol use in general and in the past week for alcohol problems, RAPI, and number of binges $(\alpha=.93$; see Table 2$)$
} 


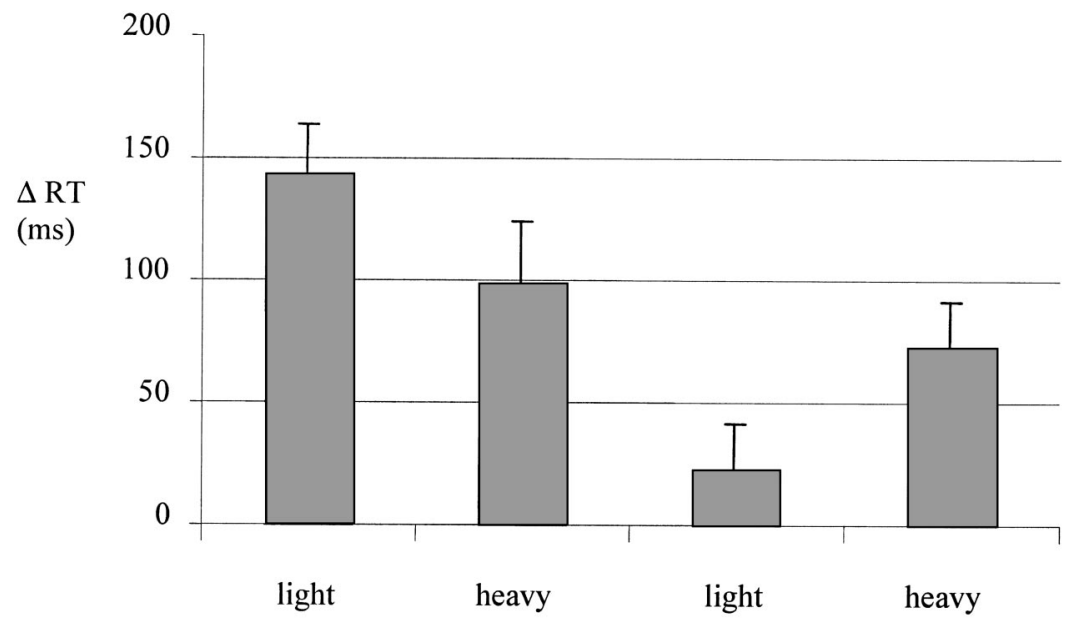

Valence IAT

Arousal IAT

Figure 1. Mean Implicit Association Test (IAT) effects for the valence IAT and the arousal IAT, with standard errors of the means. The difference scores (in reaction times [RT]) were calculated to be in the same direction for the CR phase of the valence IAT and the RC phase of the arousal IAT. A positive value for the valence IAT indicates a negative implicit association with alcohol; a positive value on the arousal IAT indicates an implicit alcohol-arousal association.

plained, $F_{\text {change }}(3,37)=8.32, p<.001, R^{2}=.45$. The only significant predictor was the combined scale of global attitudes and negative expectancies $(\beta=.54, p<.001)$. Both of the other composed explicit variables predicted nonsignificantly in the expected direction: positive reinforcement expectancies $(\beta=.26$, $p=.10)$ and negative reinforcement expectancies with sedation $(\beta=.22, p=.11)$. In Step 3 , the combined implicit associations were entered, which significantly increased the variance explained, $F_{\text {change }}(1,36)=5.09, p=.03, R^{2}=.52$. In the final model, significant predictors were the combined global attitudes and negative expectancies $(\beta=.50, p<.001)$ and the combined implicit associations $(\beta=-.28, p=.03$, in the expected direction: negative implicit associations minus implicit arousal).

\section{Discussion}

The present study compared implicit and explicit cognitivemotivational variables in light and heavy drinkers, matched for gender. The first main finding was that on the implicit measures, heavy and light drinkers differed significantly in their implicit arousal associations but not in their implicit valence associations. As hypothesized, heavy drinkers showed strong implicit associations between alcohol and arousal and light drinkers did not. This difference between heavy and light drinkers in implicit arousal associations was paralleled by a difference in explicit arousal expectancies. Gender effects were not consistent over implicit and explicit measures: On explicit arousal expectancies, women scored higher in the absence of an interaction with drinker type, and the implicit arousal associations were more robust over sessions in male heavy drinkers. Second, and contrary to our hypothesis, both light and heavy drinkers showed strong negative implicit associations with alcohol. The negative implicit association tended to be somewhat stronger for light drinkers, but this difference was not significant and varied for male and female participants across sessions. The negative implicit associations in light and heavy drinkers contrasted with their explicit positive global attitudes (and heavy drinkers were more positive than light drinkers). Third, 1-month prospective alcohol use was primarily predicted by explicit global attitudes, but implicit associations uniquely added to the prediction.

\section{Implicit Arousal Expectancies}

The IAT was developed in social cognition research, in which attributes are routinely assessed in one dimension only: positivenegative (valence) to assess implicit attitudes. The present findings indicate the importance of assessing the arousal-sedation dimension in addition to the valence dimension in addiction research. In one other recent application of the IAT to psychopathology research, Teachman et al. (2001) measured implicit associations in phobics in other dimensions than valence. Although these applications show promise for experimental psychopathology research, the present study also indicates a caveat: When more than one IAT is used, order effects between the different IATs may occur in addition to the well-documented order effects within an IAT (Greenwald \& Nosek, 2001).

The present finding that heavy and light drinkers differed in their implicit arousal associations and their explicit arousal expectancies is consistent with semantic network approaches in expectancy research (Goldman et al., 1999). One may question whether this difference between light and heavy drinkers is caused by their different drinking histories. Cross-sectional MDS research with children has indicated that children who drink more also score higher on the arousal dimension, suggesting that arousal associations develop with increased use (Dunn \& Goldman, 1998). Lon- 
gitudinal research is needed to investigate the directionality of the alcohol-arousal association.

The finding that heavy and light drinkers primarily differ in their implicit arousal associations and not in implicit valence could be related to the incentive-sensitization theory of the etiology of addictive behaviors, which tries to explain why addiction typically develops gradually and despite decreased "liking" of the drug (Robinson \& Berridge, 1993). According to this theory, "wanting" (sensitized arousal) and "liking" (valence) are independent processes, with "wanting" rather than "liking" representing the motivational process behind the etiology of alcohol and drug abuse. With repeated drug use, the mesolimbic dopaminergic "wanting" system gets sensitized: It shows a progressive increase in the initial psychomotor activating response to a drug. In this process, "incentive salience" is attributed to drug-related stimuli. As a result, these stimuli will increasingly capture attention with the behavioral outcomes of arousal and craving. Sensitization may occur in the absence of conscious awareness of participants (p. 254). In fact, the authors predicted that "much of the time, the attribution of incentive salience may be more implicit than explicit" (p. 267). Recently, the authors noted that their theory is now supported by a wealth of animal data but has not yet been critically tested in humans (Robinson \& Berridge, 2001). The present study may be a case in point.

Note that the development of implicit drug-arousal associations as a mechanism underlying the etiology of addiction is related to the "attentional bias" view, but not equivalent. Several studies have demonstrated that addicted people show an attentional bias for cues relating to their drug of abuse (see Franken, Kroon, Wiers, $\&$ Jansen, 2000). From the current perspective, drug cues not only automatically capture attention but also automatically trigger arousal associations. These arousal associations could reflect an appetitive response directed toward the drug, which may occur outside awareness (an "unconscious emotion"; see Berridge \& Winkielman, in press). Subjective craving could result from becoming aware of different aspects of drug-information processing: attention for a drug cue (attentional bias), a drug-approach actiontendency (present perspective), or a disrupted, automatized drug self-administration sequence (Tiffany, 1990).

\section{Implicit and Explicit Cognitive-Motivational Constructs}

The second main finding of this study may come as a surprise: Both light and heavy drinkers showed strong negative implicit associations with alcohol, whereas their explicit attitudes were positive, especially in heavy drinkers. A similar dissociation between implicit and explicit attitudes was found by Swanson, Rudman, and Greenwald (2001): Both smokers and nonsmokers showed strong negative associations with smoking (on the IAT), and smokers scored higher on explicit attitudes.

These findings could be interpreted as support for the conceptual difference between specific expectancies and global attitudes (see introduction). Global attitudes may reflect society's stable negative evaluation of an attitude-object (stigmatization; Swanson et al., 2001). One may wonder what exactly the attitude-object is in the present study. De Houwer (2001) showed that the category labels rather than the individual words determine the IAT effect: British students showed an implicit preference for "countrymen" versus "foreigners" (used as labels), even for liked foreigners and disliked countrymen. Hence, the results on the valence IAT show that drinkers have a strong implicit negative association with alcohol, but this does not necessarily reflect their associations with specific examplars (e.g., beer, wine). Children are primarily negative about alcohol before they initiate drinking (Wiers et al., 1998, 2000), which probably reflects society's global negative evaluation of alcohol. With increased drug use, arousal associations with drug cues could become more important. A possible explanation for the relatively positive explicit attitudes of substance users and abusers is that their (implicit) arousal associations are "mistranslated" into positive outcomes: Normally, the appetitive response is triggered by something positive (e.g., food, a sexual partner); however, in the case of drugs of abuse, this mechanism is triggered by a sensitized drug cue (Robinson \& Berridge, 1993). The underlying motivational "wanting" mechanism is interpreted as "liking" ("I often drink, so I must like it"). Another explanation could be that people have a dual attitude toward alcohol (Wilson et al., 2000). The finding that explicit and implicit cognitions uniquely contribute to the variance explained in prospective alcohol use could be interpreted as support for separate implicit and explicit processes that influence drug-related decision making (Stacy, 1997; but see Footnote 1).

Two other cognitive-motivational variables were measured: negative expectancies and negative reinforcement expectancies. Both were assessed only with explicit measures in our study (see Zack et al., 1999, for an implicit assessment of negative reinforcement expectancies) and added little to the prediction of prospective drinking. Negative reinforcement expectancies may be particularly important for a subgroup of problem drinkers: those scoring high on psychiatric distress (Zack et al., 1999). The heavy drinkers in our study (undergraduate students) drank primarily for reasons of positive reinforcement (Table 3). Negative expectancies also added little to the prediction of prospective drinking. It has been argued that negative expectancies become more important as an individual experiences more alcohol-related problems (Jones \& McMahon, 1998), which were reported with high frequency by the heavy drinkers in our study. However, negative expectancies were measured primarily as opposites of the pleasurable effects of alcohol (e.g., sad vs. happy). It is possible that a more problemfocused assessment of negative expectancies associates better with heavy drinking and motivation to change behavior (Jones \& McMahon, 1998).

\section{Limitations and Issues for Further Research}

The IAT is a promising tool to investigate implicit associations but does not come without limitations. First, the IAT always combines two attribute concepts with two target concepts. This may create some ambiguity in the interpretation of results: For example, one could argue that the difference between heavy and light drinkers on the arousal IAT found in our study is due to a difference in the soda-passive associations rather than the alcohol-active associations. In the present case, this is very unlikely given the converging evidence from alcohol expectancy research (Goldman et al., 1999) and the reported absence of soda expectancies (e.g., Query, Rosenberg, \& Tisak, 1998). Second, the IAT has a bipolar response format for both attribute and target concepts. With respect to the target-concepts, the present application was relatively unproblematic (the choice between an alcoholic 
drink and a soda is a natural one), but for other applications this may be more problematic (e.g., defining the opposite of smoking; Swanson et al., 2001). With respect to the attributes, the bipolar nature of the IAT can be criticized as well. In attitude research, the bipolar nature of attitudes is not without critics (Cacioppo \& Gardner, 1999). With respect to the arousal-sedation dimension, the distinction made in motivational theories between positive and negative reinforcement is difficult to reconcile with the single arousal dimension: A heavy drinker may expect both arousal and "relaxation" (sedation). However, memory research has indicated that heavy drinkers' first associations are with arousal (Goldman et al., 1999), and most strongly so for the rising limb of the BAC (directly after drinking alcohol; Dunn \& Earleywine, 2001). Therefore, it is likely that this problem only applies to explicit measurement, but future research could address this issue. Third, one may question the specific words used here. With respect to the targets, one could, for example, argue that "tonic" is associated with alcohol or that heavily drinking students associate hard liquor more with sedation than with arousal (note that, in both cases, the implicit association would be underestimated here). These suggestions are open to investigation. With respect to the attributes, one could argue that some of the arousal words used have a positive connotation (word choice was based on MDS research indicating that heavy drinkers most strongly expected positive arousal and light drinkers expected positive sedation). A replication with neutral arousal words would be of interest. However, the findings of de Houwer (2001) that the IAT primarily measures implicit associations between the category labels (hence, alcohol-soda with active-passive or positive-negative) makes it less likely that the choice of specific examplars would make much difference. In future studies, one could use newly developed alternatives for the IAT, without category labels (de Houwer, 2001).

The sample size of the present study was limited but comparable to other IAT studies in psychopathology research. The large effect sizes found for the implicit arousal associations in heavy drinkers, and for the negative implicit associations in light and heavy drinkers, strengthens their credibility. Furthermore, the implicit negative attitudes parallel findings in smoking research, and the implicit arousal associations in heavy drinkers parallel findings in expectancy research using more explicit techniques. Future research should determine to what extent the implicit arousal associations are moderated by gender. The power of the regression analysis was relatively small as compared with studies using less laborious implicit assessment (cf. Stacy, 1997). Therefore, it would be premature to conclude that prospective alcohol use is only predicted by explicit attitudes and implicit arousal associations and that other cognitive-motivational variables play no role. Moreover, the prospective drinking assessment period (1 month) was relatively short; a longer time frame would be of interest.

Future studies could further investigate the role of context and primes on the implicit alcohol associations. We would predict that implicit arousal associations become stronger in heavy drinkers after an alcohol-related cue or a sip of alcohol (cf. Jones \& Schultze, 2000). Similarly, alcohol cues may reinstate implicit arousal associations in abstaining alcoholics (for a similar finding in depression, see Gemar et al., 2001). From the present perspective, addicted individuals who try to abstain are torn between implicit arousal associations, triggered by drug-related cues that promote continued drug use, and explicit negative expectancies that promote a discontinuation of drug use. Further studies of implicit and explicit cognitions together may be of use in prevention and therapy research, both to suggest new interventions (Stacy \& Ames, 2001) and to better understand the effects of existing interventions. In conclusion, the present study adds to the evidence that implicit and explicit cognitions can be meaningfully distinguished and may differentially influence the development of addictive behaviors.

\section{References}

Ames, S. L., \& Stacy, A. W. (1998). Implicit cognition in the prediction of substance use among drug offenders. Psychology of Addictive Behaviors, 12, 272-281.

Beringer, J. (1996). Experimental Run Time System (ERTS), Version 3.18. Frankfurt, Germany: BeriSoft.

Berridge, K. C., \& Winkielman, P. (in press). What is an unconscious emotion? (The case of unconscious "liking"). Cognition and Emotion.

Bosson, J. K., Swann, W. B., \& Pennebaker, J. (2000). Stalking the perfect measures of implicit self-esteem: The blind man and the elephant revisited? Journal of Personality and Social Psychology, 79, 631-643.

Burden, J. L., \& Maisto, S. A. (2000). Expectancies, evaluations and attitudes: Prediction of college student drinking behavior. Journal of Studies on Alcohol, 61, 323-331.

Cacioppo, J. T., \& Gardner, W. L. (1999). Emotion. Annual Review of Psychology, 50, 191-214.

Cooper, M. L., Frone, M. R., Russell, M., \& Mudar, P. (1995). Drinking to regulate positive and negative emotions: A motivational model of alcohol use. Journal of Personality and Social Psychology, 69, 990-1005.

Cunningham, W. A., Preacher, K. J., \& Banaji, M. R. (2001). Implicit attitude measures: Consistency, stability and convergent validity. Psychological Science, 12, 163-170.

de Houwer, J. (2001). A structural and process analysis of the Implicit Association Test. Journal of Experimental Social Psychology, 37, 443451

de Jong, P. J., Pasman, W., Kindt, M., \& Van den Hout, M. A. (2001). A reaction time paradigm to assess complaint-specific (implicit) dysfunctional beliefs. Behaviour Research and Therapy, 39, 101-113.

Dovidio, J. F., Kawakami, K., \& Beach, K. R. (2001). Implicit and explicit attitudes: Examination of the relationship between measures of intergroup bias. In R. Brown \& S. Gaertner (Eds.), Handbook of social psychology: Vol. 4. Intergroup relations (pp. 175-197). Oxford, England: Blackwell.

Dunn, M. E., \& Earleywine, M. (2001). Activation of alcohol expectancies in memory in relation to limb of the blood alcohol curve. Psychology of Addictive Behaviors, 15, 18-24.

Dunn, M. E., \& Goldman, M. S. (1998). Age and drinking-related differences in the memory organization of alcohol expectancies in 3rd-, 6th-, 9th-, and 12th-grade children. Journal of Consulting and Clinical Psychology, 66, 579-585.

Earleywine, M., \& Martin, C. S. (1993). Anticipated stimulant and sedative effects of alcohol vary with dosage and limb of the blood alcohol curve. Alcoholism, Clinical and Experimental Research, 17, 135-139.

Fazio, R. H. (2001). On the automatic activation of associated evaluations: An overview. Cognition and Emotion, 15, 115-141.

Fishbein, M., \& Ajzen, I. (1975). Belief, attitude, intention and behavior: An introduction to theory and research. Reading, MA: Addison Wesley.

Franken, I. H. A., Kroon, L. Y., Wiers, R. W., \& Jansen, A. (2000). Selective processing of drug cues in heroin dependence. Journal of Psychopharmacology, 14, 395-400.

Gemar, M. C., Segal, Z. V., Sagrati, S., \& Kennedy, S. J. (2001). Moodinduced changes on the Implicit Association Test in recovered depressed patients. Journal of Abnormal Psychology, 110, 282-289.

Goldman, M. S., Del Boca, F. K., \& Darkes, J. (1999). Alcohol expectancy 
theory: The application of cognitive neuroscience. In H. T. Blane \& K. E. Leonard (Eds.), Psychological theories of drinking and alcoholism (2nd ed., pp. 203-246). New York: Guilford Press.

Greenwald, A. G., \& Banaji, M. R. (1995). Implicit social cognition: Attitudes, self-esteem, and stereotypes. Psychological Bulletin, 102, $4-27$.

Greenwald, A. G., McGhee, D. E., \& Schwartz, J. L. K. (1998). Measuring individual differences in implicit cognition. The Implicit Association Test. Journal of Personality and Social Psychology, 74, 1464-1480.

Greenwald, A. G., \& Nosek, B. A. (2001). Health of the Implicit Association Test at age 3. Zeitschrift für Experimentelle Psychologie, 48, $85-93$.

Huberty, C. J., \& Morris, J. D. (1989). Multivariate analysis versus multiple univariate analysis. Psychological Bulletin, 105, 302-308.

Jones, B. T., \& McMahon, J. (1998). Alcohol motivations as outcome expectancies. In W. R. Miller \& N. Heather (Eds.), Treating addictive behaviors: Applied clinical psychology (2nd ed., pp. 75-91). New York: Plenum.

Jones, B. T., \& Schulze, D. (2000). Alcohol-related words of positive affect are more accessible in social drinkers' memory than are other words when sip-primed by alcohol. Addiction Research, 8, 221-232.

Lang, A. R., Patrick, C. J., \& Stritzke, W. G. K. (1999). Alcohol and emotional response: A multidimensional multilevel analysis. In H. T. Blane \& K. E. Leonard (Eds.), Psychological theories of drinking and alcoholism (2nd ed., pp. 328-371). New York: Guilford Press.

Leigh, B. C. (1989a). Attitudes and expectancies as predictors of drinking habits: A comparison of three scales. Journal of Studies on Alcohol, 50, 432-440.

Leigh, B. C. (1989b). In search of the seven dwarves: Issues of measurement and meaning in alcohol expectancy research. Psychological Bulletin, 105, 361-373.

Leigh, B. C., \& Stacy, A. W. (1993). Alcohol outcome expectancies: Scale construction and predictive utility in higher order confirmatory factor models. Psychological Assessment, 5, 216-229.

Nisbett, R. E., \& Wilson, T. D. (1977). Telling more than we can know: Verbal reports on mental processes. Psychological Review, 84, 231-259.

Query, L. R., Rosenberg, H., \& Tisak, M. S. (1998). The assessment of young children's expectancies of alcohol versus a control substance. Addiction, 93, 1521-1529.

Rather, B. C., Goldman, M. S., Roehrich, L., \& Brannick, M. (1992). Empirical models of an alcohol expectancy memory network using multidimentional scaling. Journal of Abnormal Psychology, 101, 174183.

Reingold, E. M., \& Toth, J. P. (1996). Process dissociations versus task dissociations: A controversy in progress. In G. Underwood (Ed.), Implicit cognition (pp. 159-202). Oxford, England: Oxford University Press.

Robinson, T. E., \& Berridge, K. C. (1993). The neural basis of drug craving: An incentive-sensitization theory of addiction. Brain Research Reviews, 18, 247-291.

Robinson, T. E., \& Berridge, K. C. (2001). Mechanisms of action of addictive stimuli. Incentive-sensitization and addiction. Addiction, 96, 103-114.

Roefs, A., \& Jansen, A. (2002). Implicit and explicit attitudes toward high-fat foods in obesity. Journal of Abnormal Psychology, 111, 517521.

Roehrich, L., \& Goldman, M. S. (1995). Implicit activation of alcohol expectancy memory and subsequent drinking behavior. Experimental and Clinical Psychopharmacology, 3, 402-410.
Sher, K. J. (1991). Children of alcoholics: A critical appraisal of theory and research. Chicago: University of Chicago Press.

Sobell, L. C., \& Sobell, M. B. (1990). Self-report issues in alcohol abuse: State of the art and future directions. Behavioral Assessment, 12, 77-90.

Stacy, A. W. (1997). Memory activation and expectancy as prospective predictors of alcohol and marijuana use. Journal of Abnormal Psychology, 106, 61-73.

Stacy, A. W., \& Ames, S. L. (2001). Implicit cognition theory in drug use and driving under the influence interventions. In S. Sussman (Ed.), Handbook of program development in health behavior research and practice (pp. 107-130). Thousand Oaks, CA: Sage.

Stacy, A. W., Newcomb, M. D., \& Bentler, P. M. (1991). Cognitive motivation and drug use: A 9-year longitudinal study. Journal of $A b-$ normal Psychology, 100, 502-515.

Stacy, A. W., Widaman, K. F., \& Marlatt, G. A. (1990). Expectancy models of alcohol use. Journal of Personality and Social Psychology, 58, 918-928.

Swanson, J. E., Rudman, L. A., \& Greenwald, A. G. (2001). Using the Implicit Association Test to investigate attitude-behavior consistency for stigmatized behavior. Cognition and Emotion, 15, 207-230.

Teachman, B. A., Gregg, A. P., \& Woody, S. R. (2001). Implicit associations for fear-relevant stimuli among individuals with snake and spider fears. Journal of Abnormal Psychology, 110, 226-235.

Tiffany, S. T. (1990). A cognitive model of drug urges and drug-use behavior: Role of automatic and nonautomatic processes. Psychological Review, 97, 147-168.

Wall, A., Hinson, R. E., \& McKee, S. A. (1998). Alcohol outcome expectancies, attitudes toward drinking and the theory of planned behavior. Journal of Studies on Alcohol, 59, 409-419.

White, H. R., \& Labouvie, E. W. (1989). Towards the assessment of adolescent problem drinking. Journal of Studies on Alcohol, 50, 30-37.

Wiers, R. W., Gunning, W. B., \& Sergeant, J. A. (1998). Do young children of alcoholics hold more positive or negative alcohol-related expectancies than controls? Alcoholism: Clinical and Experimental Research, 22, 1855-1863.

Wiers, R. W., Hartgers, C. A., Van den Brink, W., Gunning, W. B., \& Sergeant, J. A. (2000). A confirmatory analysis of the hierarchical structure of positive and negative dose-related alcohol expectancies in alcoholics and the associations with family history of alcoholism. Journal of Studies on Alcohol, 61, 177-186.

Wiers, R. W., Hoogeveen, K. J., Sergeant, J. A., \& Gunning, W. B. (1997). High and low dose expectancies and the differential associations with drinking in male and female adolescents and young adults. Addiction, 92, 871-888.

Wiers, R. W., Sergeant, J. A., \& Gunning, W. B. (2000). The assessment of alcohol expectancies in school children: Measurement or modification? Addiction, 95, 737-746.

Wilson, T. D., Lindsey, S., \& Schooler, T. Y. (2000). A model of dual attitudes. Psychological Review, 107, 101-126.

Zack, M., Toneatto, T., \& MacLeod, C. M. (1999). Implicit activation of alcohol concepts by negative affective cues distinguishes between problem drinkers with high and low psychiatric distress. Journal of Abnormal Psychology, 108, 518-531.

Received September 14, 2001

Revision received June 5, 2002

Accepted June 13, 2002 